\title{
Frequency and characteristics of tooth agenesis among an orthodontic patient population
}

\author{
Mevlut Celikoglu ${ }^{1}$, Fatih Kazanci ${ }^{1}$, Ozkan Miloglu ${ }^{2}$, Ozkan Oztek ${ }^{1}$, Hasan Kamak ${ }^{1}$, Ismail Ceylan ${ }^{3}$ \\ ${ }^{1}$ Research Assistant, Department of Orthodontics, Faculty of Dentistry, Ataturk University, Erzurum, Turkey \\ ${ }^{2}$ Assistant Professor, Department of Oral Diagnosis and Radiology, Faculty of Dentistry, Ataturk University, Erzurum, Turkey \\ ${ }^{3}$ Professor Doctor, Department of Orthodontics, Faculty of Dentistry, Ataturk University, Erzurum, Turkey
}

Correspondence:

Department of Oral Diagnosis and Radiology

Faculty of Dentistry

Ataturk University

Erzurum, 25240, Turkey

omiloglu@hotmail.com

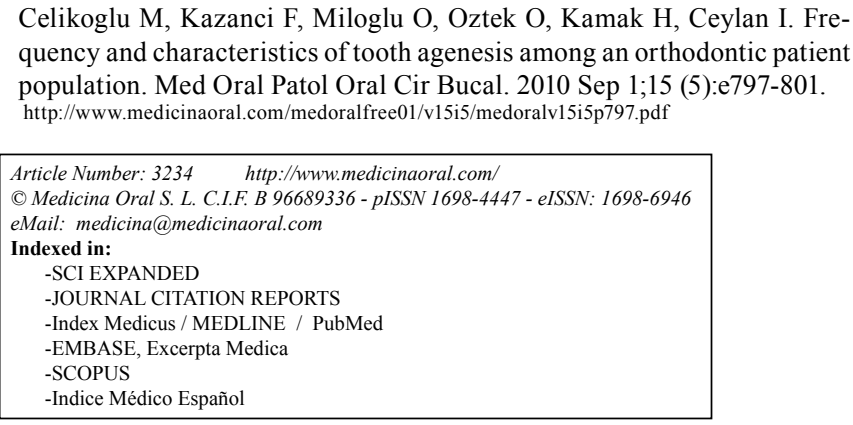

\begin{abstract}
Abstract

Purpose: The objectives of this study were to investigate the prevalence and characteristics of tooth agenesis and the associated skeletal morphology and arch widths in a group of Turkish patients seeking orthodontic treatment. Material and Methods: We designed a retrospective study composed of pre- and post-treatment panoramic radiographs and lateral cephalometric films of 3,341 patients (2,040 females and 1,301 males). Tooth agenesis was evaluated for hypodontia and oligodontia -excluding the third molars- from the orthopantomograms. The significance test for the differences in the skeletal morphology between hypodontia and non-hypodontia patients was performed using the Pearson chi-square and Student t-test.

Results: The prevalence of tooth agenesis was 4.6 percent for the Turkish orthodontic patient population. Tooth agenesis was found more frequently in females than in males, although this difference was not statistically significant ( $p>0.05$ ). The most commonly missing teeth were the maxillary lateral incisors, followed by the mandibular second premolars and mandibular central incisors. Intercanine and intermolar widths in the maxillary and mandibular arches were significantly reduced in the hypodontia group compared with the control group $(\mathrm{p}<0.01)$. Tooth agenesis was statistically and significantly less in patients with skeletal Class II $(p<0.01)$. There was no statistically significant difference in hypodontia patients in the vertical relationship of the jaws $(p>0.05)$.

Conclusions: The prevalence of tooth agenesis was found to be 4.6 percent for the Turkish orthodontic patient population (hypodontia $4.3 \%$ and oligodontia $0.3 \%$ ), and was found more frequently in females. Intercanine and intermolar widths were significantly reduced in the hypodontia group for both jaws compared with the control group.
\end{abstract}

Key words: Hypodontia, tooth agenesis, frequency. 


\section{Introduction}

Tooth agenesis is one of the most common anomalies in the development of the human dentition. The term hypodontia is used when one to five teeth, excluding the third molar, are absent. When six or more teeth, excluding the third molar, are absent, this condition is called oligodontia. Anodontia is an extreme case, denoting the complete absence of teeth (1-3).

The data for hypodontia, excluding the third molar, in both genders combined, varies from $0.3 \%$ in the Israeli population (4), $11.3 \%$ in the Irish population (5), $11.3 \%$ in Slovenian population (6), 6.3\% in Kenyan population (7), and $11.2 \%$ in Korean population (8). Silva Meza (9) reported a lower $(2.7 \%)$ hypodontia prevalence for orthodontic patients.

The effects of the tooth agenesis on dento-skeletal structures have been investigated by a limited number of authors $(6,8,10)$, although it is one of the most common anomalies in the development of the human dentition. The objectives of this study were, therefore, to investigate the prevalence and characteristics of tooth agenesis and the associated skeletal morphology and arch widths in a group of Turkish patients seeking orthodontic treatment.

\section{Material and Methods}

A total of 4,891 patients, treated between 1995 and 2008, were reviewed from the files of the Department of Orthodontics Faculty of Dentistry of Ataturk University (Erzurum, Turkey). All files included anamnestic data, panoramic radiographs, and lateral cephalometric films. Patients who were younger than 10 years old were excluded from the study. The files of patients with developmental anomalies such as ectodermal dysplasia, cleft lip or plate, Down's syndrome, or who had undergone previous orthodontic treatment were also excluded from the study. Hence, a total of 3,341 patients' records of sufficient quality were selected. All files were from Turkish patients ranging from 10 to 25 years old, 2,040 of which were females with an average age of $14.44 \pm 2.89$ years, and 1,301 of which were males with an average age of $13.94 \pm 2.49$ years.

Tooth agenesis was evaluated for hypodontia and oligodontia, excluding the third molars, from the orthopantomograms. A tooth was registered as congenitally missing when no trace could be found on radiographs and the treatment records confirmed that the tooth had not been extracted. All of the selected patients had final orthopantomograms. This final orthopantomograms was used to determine hypodontia in order to prevent the registration of late mineralized teeth as congenitally missing teeth. After determining 145 patients (84 females and 61 males) with tooth agenesis, an age- and sex-matched non-hypodontia control group (84 females and 61 males) was selected from the remaining patients using a systematic random sampling method. The lateral cephalometric films of hypodontia and non-hypodontia patients were traced and the anterior-posterior skeletal relationship of the maxilla and mandible was classified as skeletal Class I, II, and III using the measurement of the Wits and ANB angle. SN-GoGN, SN-GoMe, and Gonial angles were also measured from the lateral cephalometric films for classification of vertical skeletal relationship as being Hypo-divergent, Normal, and Hyper-divergent. Gazilerli norms were used to determine the skeletal morphology (11).

An age- and sex-matched control group of 60 subjects (40 females and 20 males) was randomly selected from the group of non-hypodontia patients. None of the subjects had crossbites, congenitally missing teeth or previous extractions, or had undergone orthodontic treatment. Subjects with crossbites or impacted or extracted canines and/or first molar teeth were excluded from the hypodontia group. Intercanine (cups tip to cusp tip) and intermolar widths (mesiobuccal cusp tip to mesiobuccal cusp tip) were measured from the dental casts of 145 subjects as the hypodontia group and 60 subjects as the control group to compare the dental arch widths (12).

\section{Statistical methods}

All descriptive and comparative statistical analyses were performed using the SPSS software package (Statistical Package for Social Sciences, version 11.5, SPSS Inc., Chicago, IL, USA). To compare the differences between male and female patients, the Pearson chi-square test was performed. The differences in the skeletal morphology between hypodontia and non-hypodontia patients were evaluated using the Pearson chi-square test. The Kolmogorov-Smirnov test was performed to test for the normality of dental arch widths parameters. Then, dental arch widths parameters were analyzed using the Student t-test for the parameters showing normal distribution (upper 3-3 and lower 3-3) and the Mann-Whitney test for the parameters showing non-normal distribution (upper 6-6 and lower 6-6).

\section{Results}

Descriptive analysis of the study groups is shown in (Table 1). Of the 3,341 cases examined, 154 patients were found to have at least one absent permanent tooth. While nine patients had six or more absent permanent teeth (i.e., oligodontia patients), 145 patients had one to five absent permanent teeth (i.e., hypodontia patients). The prevalence of hypodontia and oligodontia were 4.3 and 0.3 percent, respectively. So the prevalence of tooth agenesis was 4.6 percent in the sample of Turkish orthodontic patients. Tooth agenesis was found more frequently in females than in males. However, this difference was not statistically significant $(\mathrm{p}>0.05)$.

Distribution of missing teeth according to the jaws, sides, and regions is also shown in (Table 2). Patients 
with tooth agenesis had a total of 329 teeth. It was more commonly seen in the maxilla (60.2\%) than in the mandible (39.8\%) and in the anterior segment (63.5\%) than in the posterior (36.5\%). However, missing teeth were almost equally distributed between the right and left sides. According to the type of the missing teeth, maxillary lateral incisors $(46.5 \%)$ were the most frequent congenitally missing teeth in the Turkish orthodontic patient population, followed by mandibular second premolars $(22.5 \%)$ and mandibular central incisors (13.4\%).

The skeletal morphology for hypodontia and non-hypodontia patients is shown in (Table 3). The frequency of hypodontia patients in those Class I, Class II, and Class III malocclusion was $53.4 \%, 34.2 \%$, and $59.0 \%$, respectively. The Pearson chi-square test was used to determine the differences in the skeletal morphology between hypodontia and non-hypodontia patients, and hypodontia was found to be statistically significantly less in patients with skeletal Class II $(\mathrm{p}<0.01)$. There was no statistically significant difference in hypodontia patients in the vertical relationship of the jaws $(p>0.05)$. The intercanine widths in the hypodontia group were reduced by 3.20 and $1.17 \mathrm{~mm}$ in the maxillary and mandibular arches, respectively $(\mathrm{p}<0.01)$. Intermolar widths in the maxillary and mandibular arches were statistically significantly reduced in the hypodontia group, compared with control group $(\mathrm{p}<0.01)$ (Table 4).

Table 1. Descriptive analysis.

\begin{tabular}{|c|c|c|c|c|c|}
\hline \multicolumn{2}{|c|}{ STUDY SAMPLE } & $\begin{array}{c}\text { Females } \\
\text { n (\%) }\end{array}$ & $\begin{array}{c}\text { Males } \\
\text { n (\%) }\end{array}$ & $\begin{array}{c}\text { Total } \\
\text { n (\%) }\end{array}$ & $\begin{array}{c}\text { p } \\
\text { value }\end{array}$ \\
\cline { 3 - 5 } & 2040 & 1301 & 3341 & \\
$\begin{array}{c}\text { PATIENTS WITH } \\
\text { TOOTH AGENESIS }\end{array}$ & Hypodontia & $97(4,8)$ & $48(3,7)$ & $145(4,3)$ & \multirow{2}{*}{0,09} \\
\cline { 2 - 5 } & Oligodontia & $7(0,3)$ & $2(0,2)$ & $9(0,3)$ & \\
\cline { 2 - 5 } & Total & $104(5,1)$ & $50(3,8)$ & $154(4,6)$ & \\
\hline
\end{tabular}

Table 2. Distribution of missing teeth according to location.

\begin{tabular}{|c|c|c|c|c|c|c|c|}
\hline & \multirow{2}{*}{ Missing Teeth } & \multicolumn{2}{|c|}{ Females } & \multicolumn{2}{|c|}{ Males } & \multicolumn{2}{|c|}{ Total } \\
\hline & & $\mathbf{n}$ & $\%$ & $\mathbf{n}$ & $\%$ & $\mathbf{n}$ & $\%$ \\
\hline \multirow{2}{*}{ Side } & Right & 119 & 70.0 & 51 & 30.0 & 170 & 51,7 \\
\hline & Left & 105 & 66.0 & 54 & 34.0 & 159 & 48,3 \\
\hline \multirow{2}{*}{ Region } & Anterior & 139 & 66.5 & 70 & 33.5 & 209 & 63,5 \\
\hline & Posterior & 85 & 70.8 & 35 & 39.2 & 120 & 36,5 \\
\hline \multirow{2}{*}{ Jaw } & Maxilla & 130 & 65.7 & 68 & 34.3 & 198 & 60,2 \\
\hline & Mandible & 94 & 71.8 & 37 & 28.2 & 131 & 39,8 \\
\hline \multirow{4}{*}{ Types } & Upper lateral incisor & 96 & 62.7 & 57 & 37.3 & 153 & 46.5 \\
\hline & Lower second premolar & 49 & 66.2 & 25 & 33.8 & 74 & 22.5 \\
\hline & Lower central incisor & 34 & 77.3 & 10 & 22.7 & 44 & 13.4 \\
\hline & The others & 94 & 62.7 & 56 & 37.3 & 150 & 17.6 \\
\hline
\end{tabular}

Table 3. Skeletal features of non-hypodontia and hypodontia patients.

\begin{tabular}{|c|c|c|c|c|c|c|c|c|}
\hline \multirow{2}{*}{\multicolumn{2}{|c|}{ Skeletal Morphology }} & \multicolumn{2}{|c|}{$\begin{array}{c}\text { Non } \\
\text { hypodontia }\end{array}$} & \multicolumn{2}{|c|}{ Hypodontia } & \multicolumn{2}{|c|}{ Total } & \multirow{2}{*}{$\begin{array}{c}\mathbf{p} \\
\text { value }\end{array}$} \\
\hline & & n & $\%$ & $\mathbf{n}$ & $\%$ & n & $\%$ & \\
\hline \multirow{3}{*}{$\begin{array}{l}\text { Anterior-Posterior } \\
\text { Relationship }\end{array}$} & Class I & 61 & 46,6 & 70 & 53,4 & 131 & 100 & \multirow{3}{*}{0,004} \\
\hline & Class II & 50 & 65,8 & 26 & 34,2 & 76 & 100 & \\
\hline & Class III & 34 & 41,0 & 49 & 59,0 & 83 & 100 & \\
\hline \multirow{3}{*}{ Vertical Relationship } & Hypodivergent & 12 & 54,5 & 10 & 45,5 & 22 & 100 & \multirow{3}{*}{0,545} \\
\hline & Normal & 52 & 46,0 & 61 & 54,0 & 113 & 100 & \\
\hline & Hyperdivergent & 81 & 52,3 & 74 & 47,7 & 155 & 100 & \\
\hline
\end{tabular}


Table 4. Mean dental arch widths of nonhypodontia and hypodontia patients.

\begin{tabular}{|c|c|c|c|c|c|}
\hline \multirow[t]{2}{*}{$\begin{array}{l}\text { Dental arch } \\
\text { widths }\end{array}$} & \multicolumn{2}{|c|}{$\begin{array}{c}\text { Non- } \\
\text { hypodontia } \\
\text { group }(n=60)\end{array}$} & \multicolumn{2}{|c|}{$\begin{array}{c}\text { Hypodontia } \\
\text { group }(n=145)\end{array}$} & \\
\hline & Mean & SD & Mean & SD & $\begin{array}{c}\mathbf{p} \\
\text { value }\end{array}$ \\
\hline $\begin{array}{l}\text { Maxillary } \\
\text { intercanine } \\
\text { width }(\mathbf{m m})\end{array}$ & 33,54 & 1,65 & 30,34 & 3,56 & \multirow[b]{2}{*}{0,001} \\
\hline $\begin{array}{l}\text { Mandibular } \\
\text { intercanine } \\
\text { width (mm) }\end{array}$ & 26,18 & 1,55 & 25,01 & 2,46 & \\
\hline $\begin{array}{l}\text { Maxillary } \\
\text { intermolar } \\
\text { width (mm) }\end{array}$ & 51,69 & 2,13 & 49,23 & 3,35 & \multirow[b]{2}{*}{0,006} \\
\hline $\begin{array}{l}\text { Mandibular } \\
\text { intermolar } \\
\text { width (mm) }\end{array}$ & 45,23 & 1,97 & 44,27 & 2,84 & \\
\hline
\end{tabular}

\section{Discussion}

Calcifications of crowns of the permanent teeth, except the third molars, start at the age three and are generally complete by the age six (13). In some individuals, there may be delayed development of premolars; hence, no one can be absolutely certain that these teeth are missing below the age of about nine years, especially among males (7). Wisth et al. (12) proved that the prevalence of missing teeth is higher when examined at the age of seven years compared with nine years of age. At seven, 7.1 percent of the children had missing teeth, while two years later, only 6.6 percent of the same sample was diagnosed with hypodontia. For that reason, only patients older than 10 years old were included in the present study sample.

In the present study, the prevalence of hypodontia and oligodontia, excluding the third molars, was found to be $4.3 \%$ and $0.3 \%$, respectively. So, the total tooth agenesis prevalence was 4.6 percent, with a higher frequency in females. This result is consistent with most of the previous studies $(4,9,14-16)$. The reported frequency of hypodontia varies among different ethnic groups, ranging from $3.4 \%$ to $10.1 \%(10,13)$. The wide range of frequency rates of hypodontia can be attributed to differences in the methods of sampling and examination and the distribution of age, sex, and racial origin of the subjects.

Many studies have demonstrated that there was no consistent finding as to which jaw has more missing teeth $(4,7,9,12,17-19)$. However, Chung et al. (8) found that hypodontia was significantly more in the mandible. Tooth agenesis, in the present study, was more commonly seen in the maxilla, which is consistent with Fekonja (6). Few studies have compared the prevalence rates of tooth agenesis between the anterior and posterior regions (7). Endo et al. (10) found that anterior tooth agenesis was predominant in children with one or two missing teeth. In agreement with our results, Albashaireh et al. (20) determined that there were no statistically significant differences in the number of missing teeth between the left and right sides of the jaw. The types of teeth reported missing varies in different ethnic groups (8). Polder et al. (21) stated that the maxillary lateral incisors and the mandibular second premolar are the most frequently affected in the Caucasian population, which is in accordance with our results. We found that the maxillary lateral incisors were the most frequent congenitally missing teeth followed by the mandibular second premolars. We also observed a significant number of missing mandibular central incisors. This result was quite different from the previous studies $(7,22,23)$. However, Davis (18) and Niswander et al. (24) reported that the mandibular incisor was the most frequently absent tooth in the Chinese and Japanese populations.

Using ANB to evaluate the anteroposterior relationship of the jaws leaves considerable room for inaccuracy. Given the literature (25) showing the weakness of ANB, it seemed that the ANB and Wits measurements should have been used in order to reliably assess the jaw relationship. The skeletal morphology of hypodontia patients includes a tendency towards skeletal Class III pattern $(6,8)$. However, the skeletal characteristics of hypodontia, in the present study, showed that patients with skeletal Class II were significantly less affected by hypodontia compared with the control group. Chung et al. (8) found that the vertical relationship for hypodontia patients in the Korean population shows with a similar prevalence in Hyper-divergent, Normal, and Hypo-di- 
vergent groups. In agreement with the data reported in the Korean population, our results showed no statistically significant difference in hypodontia patients in the vertical relationship of the jaws.

Some studies found few differences in dental arch dimensions between patients with tooth agenesis and controls $(12,26)$. Nevertheless, Bu et al. (27) suggested that oligodontia patients have greater reductions in their dental arch dimensions than those with hypodontia. Salmon et al. (28) reported decreased arch widths in a large French male group with missing and small maxillary lateral incisors. However, they measured only arch dimensions in the maxilla and evaluated only lateral incisors absence. In the present study, there was a statistically significant reduction in dental arch widths for both jaws in the hypodontia group compared with the control group. The intercanine width in the maxilla was reduced by $3.20 \mathrm{~mm}$, which was the biggest reduction of dental arch widths. This might be the due to the early loss of the deciduous lateral incisor in the maxilla. Similarly, because of the retention of the deciduous second molar in the mandible, when the permanent second premolar was absent, the intermolar width in the mandible was reduced by $0.96 \mathrm{~mm}$, which was the smallest reduction of dental arch widths.

\section{Conclusion}

The prevalence of tooth agenesis was found to be 4.6 percent for the Turkish orthodontic patient population (hypodontia $4.3 \%$ and oligodontia $0.3 \%$ ). Tooth agenesis was more frequently found in females than in males and in the maxilla than in the mandible. The most frequently missing teeth were the maxillary lateral incisors, followed by the mandibular second premolars and the mandibular central incisors. The majority of patients had one or two teeth missing, but seldom three or more. Hypodontia was significantly less in patients with skeletal Class II $(\mathrm{p}<0.01)$. There was no statistically significant difference in hypodontia patients in the vertical relationship of the jaws $(p>0.05)$. Intercanine and intermolar widths were significantly reduced in the hypodontia group for both jaws compared with control group $(\mathrm{p}<0.01)$.

\section{References}

1. Peker I, Kaya E, Darendeliler-Yaman S. Clinic and radiographical evaluation of non-syndromic hypodontia and hyperdontia in permanent dentition. Med Oral Patol Oral Cir Bucal. 2009;14:e393-7.

2. Kolenc-Fusé FJ. Tooth agenesis: in search of mutations behind failed dental development. Med Oral Patol Oral Cir Bucal. 2004;9:390-5; 385-90.

3. Alves-Pereira D, Berini-Aytés L, Gay-Escoda C. Ellis-van Creveld syndrome. Case report and literature review. Med Oral Patol Oral Cir Bucal. 2009;14:E340-3.

4. Rosenzweig KA, Garbarski D. Numerical aberrations in the permanent teeth of grade school children in Jerusalem. Am J Phys Anthropol. 1965;23:277-83.
5. O'Dowling IB, McNamara TG. Congenital absence of permanent teeth among Irish school-children. J Ir Dent Assoc. 1990;36:136-8.

6. Fekonja A. Hypodontia in orthodontically treated children. Eur J Orthod. 2005;27:457-60.

7. Ng'ang'a RN, Ng'ang'a PM. Hypodontia of permanent teeth in a Kenyan population. East Afr Med J. 2001;78:200-3.

8. Chung CJ, Han JH, Kim KH. The pattern and prevalence of hypodontia in Koreans. Oral Dis. 2008;14:620-5.

9. Silva Meza R. Radiographic assessment of congenitally missing teeth in orthodontic patients. Int J Paediatr Dent. 2003;13:112-6.

10. Endo T, Ozoe R, Kubota M, Akiyama M, Shimooka S. A survey of hypodontia in Japanese orthodontic patients. Am J Orthod Dentofacial Orthop. 2006;129:29-35.

11. Gazilerli U. (Master Thesis) The Steiner norms between 13-16 years old Turkish children with the normal occlusion on the region of Ankara. Ankara University Faculty of Dentistry Department of Orthodontics. 1976.

12. Wisth PJ, Thunold K, Böe OE. Frequency of hypodontia in relation to tooth size and dental arch width. Acta Odontol Scand. 1974;32:201-6.

13. Zhu JF, Marcushamer M, King DL, Henry RJ. Supernumerary and congenitally absent teeth: a literature review. J Clin Pediatr Dent. 1996;20:87-95.

14. Nordgarden H, Jensen JL, Storhaug K. Reported prevalence of congenitally missing teeth in two Norwegian counties. Community Dent Health. 2002;19:258-61.

15. Mattheeuws N, Dermaut L, Martens G. Has hypodontia increased in Caucasians during the 20th century? A meta-analysis. Eur J Orthod. 2004;26:99-103.

16. Dhanrajani PJ. Hypodontia: etiology, clinical features, and management. Quintessence Int. 2002;33:294-302.

17. Harris EF, Clark LL. Hypodontia: an epidemiologic study of American black and white people. Am J Orthod Dentofacial Orthop. 2008;134:761-7.

18. Davis PJ. Hypodontia and hyperdontia of permanent teeth in Hong Kong schoolchildren. Community Dent Oral Epidemiol. 1987;15:218-20.

19. Bergström K. An orthopantomographic study of hypodontia, supernumeraries and other anomalies in school children between the ages of 8-9 years. An epidemiological study. Swed Dent J. 1977; 1:145-57.

20. Albashaireh ZS, Khader YS. The prevalence and pattern of hypodontia of the permanent teeth and crown size and shape deformity affecting upper lateral incisors in a sample of Jordanian dental patients. Community Dent Health. 2006;23:239-43.

21. Polder BJ, Van't Hof MA, Van der Linden FP, Kuijpers-Jagtman AM. A meta-analysis of the prevalence of dental agenesis of permanent teeth. Community Dent Oral Epidemiol. 2004;32:217-26.

22. Muller TP, Hill IN, Peterson AC, Blayney JR. A survey of congenitally missing permanent teeth. J Am Dent Assoc. 1970;81:101-7. 23. Ingervall B, Seeman L, Thilander B. Frequency of malocclusion and need of orthodontic treatment in 10-year old children in Gothenburg. Sven Tandlak Tidskr. 1972;65:7-21.

24. Niswander JD, Sujaku C. Congenital anomalies of teeth in Japanese children. Am J Phys Anthropol. 1963;21:569-74.

25. Oktay H. A comparison of ANB, WITS, AF-BF, and APDI measurements. Am J Orthod Dentofacial Orthop. 1991;99:122-8.

26. Woodworth DA, Sinclair PM, Alexander RG. Bilateral congenital absence of maxillary lateral incisors: a craniofacial and dental cast analysis. Am J Orthod. 1985;87:280-93.

27. Bu X, Khalaf K, Hobson RS. Dental arch dimensions in oligodontia patients. Am J Orthod Dentofacial Orthop. 2008;134:768-72.

28. Salmon D, Le Bot P. Congenital defects of the upper lateral incisors: multivariate analysis of measurements of the other teeth, the superior arch, head and face. Am J Phys Anthropol. 1977;46:245-51. 